Article

\title{
Ceriporia lacerata Mycelium Culture Medium as a Novel Anti-Aging Microbial Material for Cosmeceutical Application
}

\author{
Jeong-Hwan Kim ${ }^{1,2}, *$, Changhun An ${ }^{3}$, Seong Deok Hwang ${ }^{3}$ and Yoon Soo Kim ${ }^{1}$ \\ 1 Bio-R\&D Center, FugenBio Co., Ltd., Seoul 06740, Korea; paul.kim@fugenbio.com \\ 2 Cardiovascular Research Institute, Graduate School of Medicine, Yokohama City University, 3-9 Fukuura, \\ Kanazawa-ku, Yokohama 236-0004, Japan \\ 3 FugenCellTech Co., Ltd., Sangju-si 37272, Gyeongsangbuk-do, Korea; changhun.an@fugenbio.com (C.A.); \\ sd.hwang@fugenbio.co.kr (S.D.H.) \\ * Correspondence: jeongkim@yokohama-cu.ac.jp or jeonghwan.kim@fugenbio.com
}

check for

updates

Citation: Kim, J.-H.; An, C.; Hwang, S.D.; Kim, Y.S. Ceriporia lacerata

Mycelium Culture Medium as a

Novel Anti-Aging Microbial Material for Cosmeceutical Application.

Cosmetics 2021, 8, 101. https://

doi.org/10.3390/cosmetics8040101

Academic Editors: Christophe Hano,

Vasil Georgiev and Duangjai

Tungmunnithum

Received: 12 October 2021

Accepted: 30 October 2021

Published: 2 November 2021

Publisher's Note: MDPI stays neutral with regard to jurisdictional claims in published maps and institutional affiliations.

Copyright: (c) 2021 by the authors. Licensee MDPI, Basel, Switzerland. This article is an open access article distributed under the terms and conditions of the Creative Commons Attribution (CC BY) license (https:// creativecommons.org/licenses/by/ $4.0 /)$.

\begin{abstract}
Skincare is very critical in preventing aging and skin trouble, which is difficult to recover if progressed. However, the development of effective anti-aging solutions is still on the horizon. The purpose of this study was to evaluate the functional efficacy of Ceriporia lacerata exo-pharmaceutical substance (CLEPS) in view of its use in innovative skin care cosmetics. CLEPS was found to have no cytotoxicity against normal human dermal fibroblasts and B16 melanoma cells in a wide concentration range of $0.05-7 \mathrm{mg} / \mathrm{mL}$. It exhibited a whitening effect by inhibiting melanin synthesis comparable to that of the respective reference compound (arbutin). Notably, CLEPS not only substantially increased collagen $(65.4 \%)$ and filaggrin synthesis (36\%), but also significantly inhibited the activity of collagenase (93.4\%), suggesting that CLEPS could prevent skin barrier damage or skin wrinkles. In addition, it showed an excellent anti-inflammatory effect and wound-healing effect. Overall, CLEPS exhibited exceptional anti-aging effects in human skin cells, designating as a potential natural cosmeceutical ingredient.
\end{abstract}

Keywords: Ceriporia lacerata; anti-aging; anti-inflammation; anti-oxidation; anti-collagenase; filaggrin upregulation; whitening; wound healing

\section{Introduction}

Among other organs, human skin is a vanguard interface constantly exposed to harmful external stimuli, such as general metabolic reactions, cosmetics, and ultraviolet (UV) irradiation. These factors lead to undesired biochemical byproducts, including reactive oxygen species (ROS), matrix metalloproteinases (MMPs), and advanced glycation end-products (AGEs), which can trigger skin aging, including wrinkles, pigmentation, and loss of skin tone [1,2]. ROS, dangerous oxygen molecules as a pleiotropic physiological signal transmitter, mainly induce cross-linking of collagen and elastin to induce wrinkles and lower skin recovery, which are considered to be the main driving force of aging caused by UV rays and pollution [3]. MMPs are enzymes activated by UV exposure or inflammation, which contribute to collagen breakdown while inhibiting the formation of new collagen [1]. The formation of AGEs is the result of the reaction of glucose with proteins, including skin collagen, which can contribute to loss of elasticity, wrinkles, inflammation, inhibition of skin cell growth, and accelerated aging [2].

Since oxidative stress is one of the metabolic factors and pathways most associated with cellular aging, the consumption of functional foods and functional cosmetics with antioxidant activity is increasing significantly. Therefore, antioxidants can be beneficial to the human body by directly or indirectly neutralizing ROS, via regulating metabolic pathways and gene expression as the main cellular activation mechanisms.

Natural metabolites derived from microbial sources have been used in a variety of applications as a nutritional source and as a skin care agent [4]. Among them, the metabolites 
derived from fungi contain biologically active ingredients of considerable commercial value, including oligosaccharides, exopolysaccharides (EPS), enzymes, peptides, vitamins, and biosurfactants. These metabolites are widely used as main raw materials for pharmaceuticals, functional foods, and cosmetic products [5-9]. Packed with thousands of antioxidants and anti-inflammatory properties, they have been widely used to fight aging by improving the skin's natural defenses, restoring skin elasticity, increasing moisture content, promoting collagen synthesis, and exhibiting skin-whitening effects [4,5]. Besides, these compounds, replacing traditional chemical ingredients, are applied in a variety of cosmetic products used to improve the health and beauty of mankind in a biosafe and detoxifying manner. In particular, the unique biocompatibility, non-toxicity, and functionality of fungal EPS have been widely employed in the cosmetic industry [4]. For instance, metabolic compounds such as Schizophyllan, a polysaccharide of $\beta-1,3 \beta$-glucan with $\beta-1,6$ branching, extracted from Schizophyllum commune, are known to help with skin anti-inflammatory and UV protection effects [10]. Galactomyces ferment filtrate (GFF) has been isolated from Galactomyces candidum to study cosmeceutical effects on reduction of facial skin pores, skin pigmentation, and relieve oxidative stress, while the mechanisms of action underlying EPS of GFF along with its compound information are still unidentified [11]. Ceriporia lacerata is a type of white putrefactive filamentous fungus that plays an important role in bioremediation by breaking down cellulose and lignin [12,13]. The bioactive efficacy of $C$. lacerata mycelium (CLM) culture has been studied to control hyperglycemia levels [14], insulin secretion through cytoprotective effects [15], and insulin signaling through activation of AMP-activated protein kinase (AMPK) and glucose transporter type 4 (GLUT4) $[16,17]$. However, the pharmacological effect of CLM on anti-oxidation and anti-aging is not yet known.

The cultured C. lacerata is composed of microscopic polypores; thus, it looks like white moss (Figure 1a). During the liquid culture process, various secondary metabolites, e.g., exo-metabolites, are generated depending on the environmental conditions (Figure $1 b$ ). However, there are no reports of C. lacerata or CLM on skin care-associated effect. Therefore, this study aimed to investigate the antioxidant, wound healing, wrinkle improvement, moisturizing, and whitening effects of CLM on the anti-aging mechanism of skin cells. To the best of our knowledge, this study is the first report to propose a new route for skincare at the cellular level based on the anti-aging mechanism using anti-diabetic ingredients derived from the culture of CLM, an emerging microorganism [14-17].

(a)

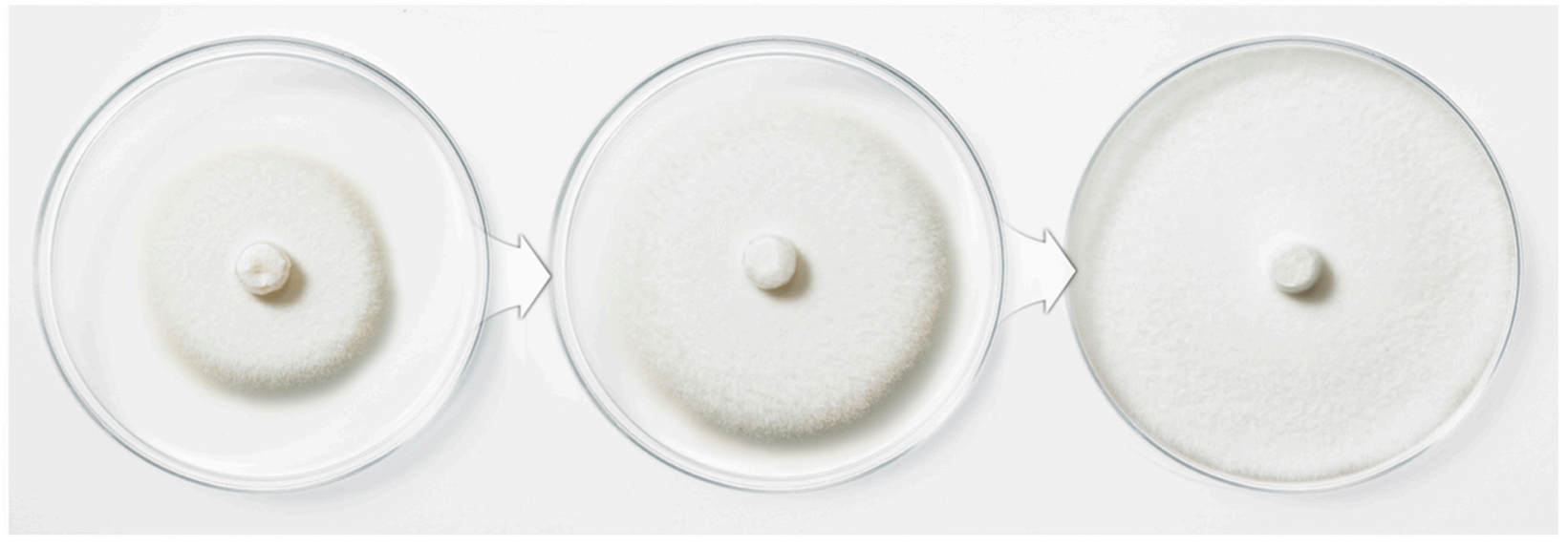

Figure 1. Cont. 
(b)

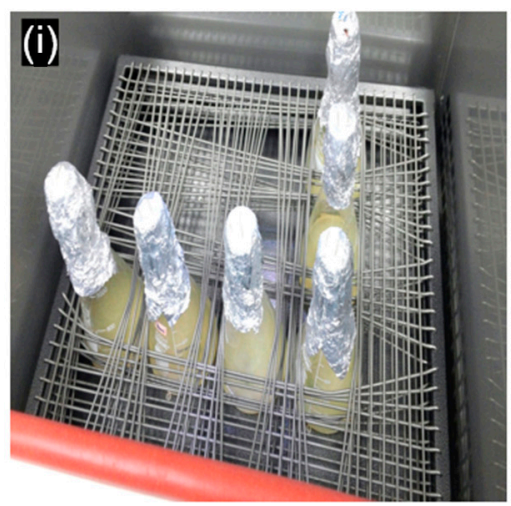

Pre-culture

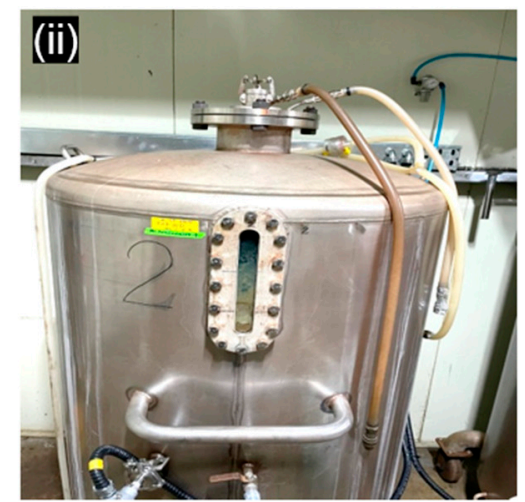

Main culture

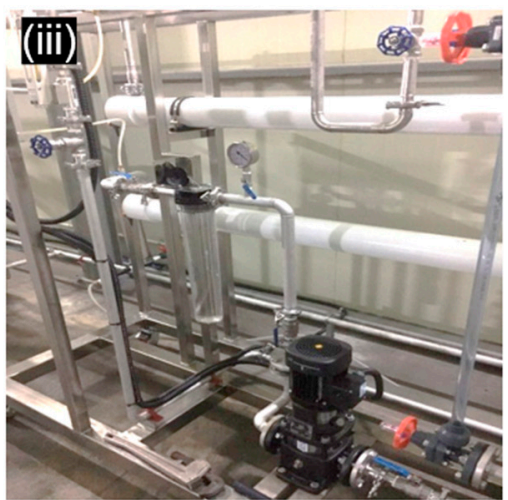

Filtration

Figure 1. Green manufacturing method of Ceriporia lacerata exo-pharmaceutical substance (CLEPS), including solid culture (a) and downstream processes (b) such as pre-culture (i), main culture (ii), and filtration (iii).

\section{Materials and Methods}

\subsection{Ceriporia Lacerata Exo-Pharmaceutical Substance Preparation}

The strain used in this experiment was used by inoculating CLM (FugenCellTech, Sangju, Korea) on potato dextrose agar (PDA, Difco. Co., Sparks, MD, USA) medium and culturing at $25{ }^{\circ} \mathrm{C}$ for 9 days. The culture broth of $C$. lacerata mycelium was precultured in a potato dextrose broth for 10 days. After pre-culturing is completed, the mycelium culture medium was mixed with glucose $(12.5 \mathrm{~g} / \mathrm{L})$, potato starch $(2.5 \mathrm{~g} / \mathrm{L})$, defatted soybean $(5 \mathrm{~g} / \mathrm{L})$, and glycerin esters of fatty acids from plant oil $(0.12 \mathrm{~g} / \mathrm{L})$ as an anti-foaming agent, following by additional incubation for 11 days at $23^{\circ} \mathrm{C}$. By taking a centrifugation to separate the precipitates, the clear supernatant of the culture medium of CLM was ultrafiltered with an ultrafiltration technique utilizing a polysulfone membrane with 3.6 8.0 $\mathrm{m}^{2}$ (molecular weight cut off: $\left.30 \sim 100 \mathrm{kDa}\right)$. The stock solution $(100 \%)$ of CLEPS was dissolved in the culture solution and used for all the biological analyses in this work, without adding any solvents, co-solvents, reagents, or chemicals, which confirms biosafe and high-quality green cosmetic ingredients.

\subsection{Measurement of Antioxidant Activity}

2.2.1. 2,2-Diphenyl-1-picryl-hydrazyl-hydrate (DPPH) Scavenging Activity Assay

Free radical scavenging ability of the CLEPS was tested by DPPH radical scavenging photometric assay according to methodology described by Choi et al. [18] and Kedare et al. [19]. The CLEPS was mixed with $90 \mathrm{mM}$ methanolic DPPH to form final solution concentrations of $0.5,1$, and $5 \mathrm{mg} / \mathrm{mL}$ in 96-well plates, which were incubated for $30 \mathrm{~min}$ at $25^{\circ} \mathrm{C}$ and the absorbance (OD) was read in a microplate reader (Multiskan GO, Thermofisher Scientific, Waltham, MA, USA) at a wavelength of $517 \mathrm{~nm}$. Three independent experiments were performed. Ascorbic acid (AA, $1 \mathrm{mg} / \mathrm{mL}$ ) was used as the positive control. DPPH inhibitory percent was calculated by following the formula below:

DPPH scavenging $\%=$ [control A0 - sample A1/control A0] $\times 100$, where A1 indicates the absorbance of sample, while $\mathrm{A} 0$ indicates the absorbance of control (methanolic solution of DPPH).

\subsubsection{2,2-Azinobis-(3-ethylbenzothiazoline-sulfonic acid) (ABTS) Radical Scavenging Activity}

Determination of the free radical scavenging activity of CLEPS solutions was achieved by ABTS radical cation decolorization assay according to a methodology described by Kedare et al. [19]. ABTS cation radical generation was accomplished by combining $10 \mathrm{mg}$ of ABTS and $2 \mathrm{mg}$ of potassium persulfate in water. The solution was placed in the dark at $25^{\circ} \mathrm{C}$ for about $12 \mathrm{~h}$ before use. ABTS solution $(1 \mathrm{~mL})$ was diluted with $60 \mathrm{~mL}$ of methanol, then the CLEPS was mixed with $90 \mu \mathrm{M}$ methanolic ABTS to form final solution concentrations of $0.5,1$, and $5 \mathrm{mg} / \mathrm{mL}$ in 96 -well plates. The plates were incubated at 
$25^{\circ} \mathrm{C}$ for $30 \mathrm{~min}$ and the OD was measured at a wavelength of $734 \mathrm{~nm}$ using a Multiskan GO instrument. Three independent experiments were performed. Ascorbic acid (AA, $1 \mathrm{mg} / \mathrm{mL}$ ) was used as the positive control. ABTS inhibitory percent was calculated by following the formula below:

ABTS scavenging $\%=[$ control A0 - sample A1/control A0] $\times 100$ where A1 indicates the absorbance of sample, while $\mathrm{A} 0$ indicates the absorbance of control (methanolic solution of ABTS).

\subsection{Cell Viability Assay}

To evaluate cell viability of CLEPS on the skin cells, the human dermal fibroblasts (NHDF) (ATCC) were cultured in DMEM (high glucose) (WelGENE, KR) supplemented with $10 \%$ fetal bovine serum (FBS) (WelGENE, Gyeongsan, Korea) and $1 \%$ penicillin/streptomycin (WelGENE, Gyeongsan, Korea) at $37^{\circ} \mathrm{C}$ in a $5 \% \mathrm{CO}_{2}$ incubator (UP50H, Forma Scientific, Marietta, OH, USA). The cells were incubated at $7 \times 10^{4}$ cells/well in a 12 well plate. After confirming the cell adhesion, it was transferred to a serum-free media and the solutions were treated at a working concentration in each well for $72 \mathrm{~h}$. The thiazolyl blue tetrazolium bromide (MTT) (Sigma, St. Louis, MO, USA) solution at a concentration of $100 \mu \mathrm{g} / \mathrm{mL}$ was added to each well and incubated at $37^{\circ} \mathrm{C}, 5 \% \mathrm{CO}_{2}$ for $2 \mathrm{~h}$. Then, all the culture medium was removed and $500 \mu \mathrm{L}$ of DMSO (Duchefa Biochemicals, Haarlem, The Netherlands) was added to each well. The absorbance at $570 \mathrm{~nm}$ was measured with an ELISA reader (Epoch, Bio-tek INC, Winooski, VT, USA). The cell culture medium was used as a negative control (control (-)).

\subsection{Expression Level of Filaggrin}

To showcase how CLEPS influences the skin barrier function, the mRNA expression level of filaggrin was measured by a RT-PCR. HaCaT cell was cultured at $2 \times 10^{4}$ cells/well in a 24 -well plate using DMEM medium containing $10 \%$ FBS, $1 \%$ penicillin, and $1 \%$ streptomycin, and then cultured at $37^{\circ} \mathrm{C}, 5 \% \mathrm{CO}_{2}$ incubator for $24 \mathrm{~h}$. After removal of the supernatant, each sample was added in DMEM medium excluding FBS for $24 \mathrm{~h}$ at $37^{\circ} \mathrm{C}$, $5 \% \mathrm{CO}_{2}$ incubator. After incubation, the supernatant was removed and the RNA harvested according to the manual using Easy Blue lysis reagent (iNtRON Biotechnology, Seongnam, Korea). RT PreMix (BIONEER, Daejeon, Korea) was used at $42{ }^{\circ} \mathrm{C}$ for $60 \mathrm{~min}$ and $95^{\circ} \mathrm{C}$ for 5 min to synthesize cDNA. The PCR primers (Macrogen, Daejeon, Korea) were designed as presented in Table 1 and Western blotting was performed to determine the amount of filaggrin expression.

Table 1. RT-PCR primers used in the filaggrin assay.

\begin{tabular}{cccc}
\hline Genes & Sequences & Accession No. & Amplicon Size, bp \\
\hline \multirow{2}{*}{-actin (Human) } & $\begin{array}{c}\text { Forward 5'-GTCACCAACTGGGACGACATG-3 } \\
\text { Reverse 5'-GCCGTCAGGCAGCTCGTAGC-3' }\end{array}$ & NC_000019 & 640 \\
\hline Filaggrin (Human) & $\begin{array}{c}\text { Forward 5'-TGATGCAGTCTCCCTCTGTG-3 } \\
\text { Reverse 5'-TGTTTCTCTTGGGCTCTTGG-3' }\end{array}$ & NC_000001 & 610 \\
\hline
\end{tabular}

To measure the protein level of filaggrin, each cell was aliquoted in a 6-well plate at $1 \times 10^{5}$ cells/well using DMEM medium containing $10 \%$ FBS, $1 \%$ penicillin, and $1 \%$ streptomycin, followed by $24 \mathrm{~h}$ incubation. After the supernatant solution was removed and refilled with fresh medium, the cells were further cultured for $24 \mathrm{~h}$. The plate from which the supernatant was removed was treated with Protein Solution (iNtRON Biotechnology, Seongnam, Korea) to lyse the cells, and then centrifuged (13,000 rpm, $15 \mathrm{~min}, 4^{\circ} \mathrm{C}$ ). Then, to measure the protein concentration in the supernatant, it was mixed with $30 \mu \mathrm{g}$ NuPAGE LDS sample buffer (Novex, CA) and boiled at $100{ }^{\circ} \mathrm{C}$ for $5 \mathrm{~min}$. Subsequently, the protein was transferred to transfer membranes (Millipore, Burlington, MA, USA) after SDS-PAGE using Mini PROTEAN ${ }^{\circledR}$ Tetra cells (552BR, Bio-Rad, Hercules, CA, USA). Non-specific protein binding portions were blocked by reacting with Tris-buffered 
saline with $0.1 \%$ Tween ${ }^{\circledR} 20$ (TBST) and 5\% skim milk for $1 \mathrm{~h}$. The primary antibody (filaggrin: Santa Cruz Biotechnology, Dallas, TX, USA) was diluted to 1:1000 $(v / v)$, stirred overnight at $4{ }^{\circ} \mathrm{C}$, and washed 3 times with TBST for $15 \mathrm{~min}$. Then, the secondary antibody solution was added, following by stirring at $25^{\circ} \mathrm{C}$ for $1 \mathrm{~h}$ and washing 3 times with TBST for $15 \mathrm{~min}$, and then Immobilon western Chemiluminescent HRP Substrate (MerckMillipore, Darmstadt, Germany) was used to blot the bands, which were imaged with Omega Lum G (Aplegen, Pleasanton, CA, USA). As an internal standard protein, $\beta$-actin (Sigma, St. Louis, MO, USA) was used.

\subsection{Melanogenesis Inhibition Test of B16 Melanoma Cells}

To find safe doses for melanin inhibition assay and observe the inhibition activity of melanin by the CLEPS sample treatment, B16 melanoma cells (ATCC) at $1 \times 10^{5}$ cells/well were cultured in a 6-well culture plate containing DMEM medium with 10\% FBS and $1 \%$ penicillin-streptomycin added at $37{ }^{\circ} \mathrm{C}$ and $5 \% \mathrm{CO}_{2}$ condition. A melanin synthesis inducer, $\alpha$-melanocyte stimulating hormone $(\alpha-\mathrm{MSH})$, was prepared by dissolving it in $10 \%$ DMSO at a concentration of $50 \mu \mathrm{M}$. After incubating for $24 \mathrm{~h}$, the CLEPS solutions were added and immediately treated with $\alpha-\mathrm{MSH}(50 \mathrm{nM})$, following by additional incubation for $72 \mathrm{~h}$. Next, the cell plates were washed twice with PBS and trypsinized, and then the recovered cells were centrifuged at $5000 \mathrm{rpm}$ for $10 \mathrm{~min}$ to remove the supernatant, after which a cell pellet was obtained. The intracellular melanin content was determined according to the method previously reported with minor modification [20]: melanin was harvested by dissolving it in $2 \mathrm{~N} \mathrm{NaOH}$ containing $10 \%$ DMSO at $60^{\circ} \mathrm{C}$ for $4 \mathrm{~h}$, which was transferred to a 96-well plate. DMSO $(0.1 \% v / v)$ was the solvent for the control and the test samples with $\alpha-\mathrm{MSH}$. The absorbance was measured at $475 \mathrm{~nm}$ with an ELISA reader.

\subsection{Anti-Inflammation Assay of Nitric Oxide (NO)}

To examine the NO production, RAW 264.7 cells (ATCC) were cultured and inoculated at a density of $1 \times 10^{4}$ cells/well in a 96-well plate. The cells were exposed to CLEPS (100 or $500 \mu \mathrm{g} / \mathrm{mL}$ ) for $1 \mathrm{~h}$, followed by stimulation of the cells with lipopolysaccharide (LPS) $(1 \mu \mathrm{g} / \mathrm{mL}$ ). $10 \mu \mathrm{g} / \mathrm{mL}$ of $\alpha$-lipoic acid (LA) (Sigma) was used as a positive control. After $24 \mathrm{~h}$, the amount of $\mathrm{NO}$ in the cell medium was measured in a volume of $100 \mu \mathrm{L}$ consisting of a 1:1 ratio mixture of solution A (1\% 4-aminobenzenesulfonamide, $0.2 \%$ N1-(naphthalen1-yl) ethane-1,2-diamine dihydrochloride) and solution B (5\% phosphoric acid), which was added with an equal volume of medium. After $15 \mathrm{~min}$, the absorbance measurements were performed at $550 \mathrm{~nm}$ using a microplate reader (Multiskan GO instrument). The culture medium without LPS (normal group) was used as the negative control.

2.7. Anti-Inflammation Assay of Inducible Nitric Oxide Synthase (iNOS), Cyclooxygenase-2 (COX2), and Tumor Necrosis Factor $\alpha$ (TNF $\alpha)$

The RAW 264.7 cells $\left(5 \times 10^{4}\right.$ cells/well) on $6 \mathrm{~cm}$ dishes were cultured overnight, which were pretreated for $1 \mathrm{~h}$ with CLEPS. The cells were exposed to LPS $(1 \mu \mathrm{g} / \mathrm{mL})$ and incubated for $24 \mathrm{~h} .10 \mu \mathrm{g} / \mathrm{mL}$ of $\alpha$-lipoic acid (LA) (Sigma) was used as a positive control. After obtained the proteins using a lysis buffer (Cell Signaling Technologies, Danvers, MA, USA), it was mixed with a phosphatase inhibitor cocktail and protease (Thermo Fisher Scientific, Inc., Waltham, MA, USA), after which the whole lysates were measured using a detergent-compatible protein assay (Bio-Rad Laboratories, Inc., Hercules, CA, USA). The proteins were separated by SDS-PAGE gel electrophoresis. The transferred membranes (Immobilon ${ }^{\circledR}$-P, Millipore, Burlington, MA, USA) were blocked in TBST buffer (Sigma, St. Louis, MO, USA), which included $5 \%$ skim milk, and the membranes were kept at $4{ }^{\circ} \mathrm{C}$ with antibodies against iNOS, COX2, or TNF $\alpha$ (1:1000). The culture medium without LPS (normal group) was used as the negative control.

\subsection{Synthesis of Collagen and Inhibition of Collagenase}

The NHDF cells were cultured and pretreated with CLEPS to examine the efficacy of CLEPS on collagen formation and collagenase inhibition by taking a procollagen type I 
C-peptide EIA kit (Takara, Kusatsu, Japan) and a human pro-MMP-1 Quantikine ELISA kit (R\&D system, Minneapolis, MN, USA), respectively. As a method of measuring the activity level of collagenase, an enzyme that decomposes collagen, an antibody against collagenase (MMP-1) was used, while Phorbol 12-myristate 13-acetate (PMA) (Sigma) was used to activate the expression of MMP-1. $10 \mathrm{ng} / \mathrm{mL}$ of TGF- $\beta$ (Sigma) was dissolved in culture medium was used as a positive control, while the culture medium was the negative control.

\subsection{In Vitro Wound Healing Assay}

To examine the effect of CLEPS on wound healing, HaCaT cells $\left(1 \times 10^{4}\right.$ cells/well $)$ were plated into 12 -well plates for $48 \mathrm{~h}$ and grew to $100 \%$ confluence. The monolayer was wounded using the tip of a sterile $200 \mu \mathrm{L}$ pipette. Cell debris was removed by washing twice with PBS. These cells were then replaced with fresh $1 \%$ serum medium with or without CLEPS (100, 500 and $1000 \mu \mathrm{g} / \mathrm{mL}$ ), followed by stimulation for 0-48 h. A control group was used to compare the wound healing properties in the presence and absence of CLEPS. Photomicrographs of the wound closure (cell migration) were taken at $0-48 \mathrm{~h}$ of the same wounded areas using the inverted microscope (Zeiss, Jena, Germany). The $\%$ change of wound area in pixels was quantified manually for each image using ImageJ Software (v1.52a, National Institutes of Health, Bethesda, MD, USA).

\subsection{Statistical Analysis}

Bio-functional assays of the CLEPS in each platform were performed in triplicate. The results were expressed as the mean \pm standard deviation. Statistical analyses were carried out using ANOVA, followed by Tukey HSD post-hoc test or Student's $t$-test. These tests were performed using SPSS software (v25, International Business Machines, Armonk, NY, USA) and Microsoft Excel (v1905, Microsoft, USA). A $p$ value of $<0.05$ was considered statistically significant.

\section{Results and Discussion}

\subsection{Measurement of Antioxidant Activity}

The antioxidant activity of the solutions was evaluated by the DPPH and ABTS assays. Given the fact that most natural antioxidants hold reactive hydrogens, which serve as reductants, both DPPH and ABTS assays are a useful measure of standard antioxidant profile. As shown in Figure 2, CLEPS solution $(5 \mathrm{mg} / \mathrm{mL})$ exhibited the ability to scavenge $\sim 81 \%$ DPPH (a) and $~ 85 \%$ ABTS (b) free radicals (active oxygen) as equivalent to ascorbic acid (AA, $1 \mathrm{mg} / \mathrm{mL}$ ).

(a)

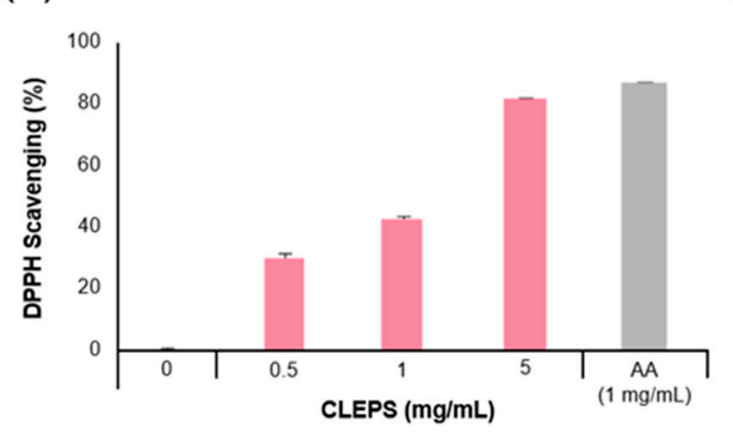

(b)

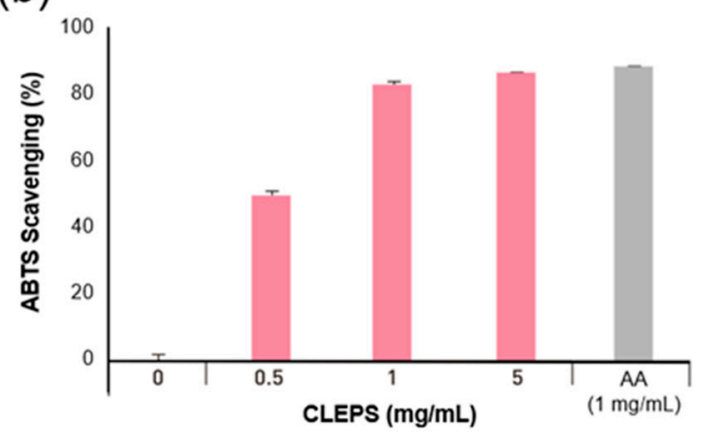

Figure 2. Anti-oxidation efficacy of CLEPS via DPPH (a) and ABTS (b) assays. $p>0.05$ vs. 0 mg/mL.

\subsection{Cell Viability Assay}

As presented in Figure 3, no toxicity on the viability of NHDF (a) and B16 melanoma cells (b) was observed when CLEPS was tested at a wide range of concentration $(0.05-7 \mathrm{mg} / \mathrm{mL})$. Moreover, it was determined that the CLEPS treatment could induce fibroblast cell proliferation in a dose-dependent manner at $1-7 \mathrm{mg} / \mathrm{mL}$. This finding was in good agreement 
with that of another study, which reported on the cell proliferation effect of a bioactive polysaccharide extract from Auricularia auricula-judae mushrooms [21].

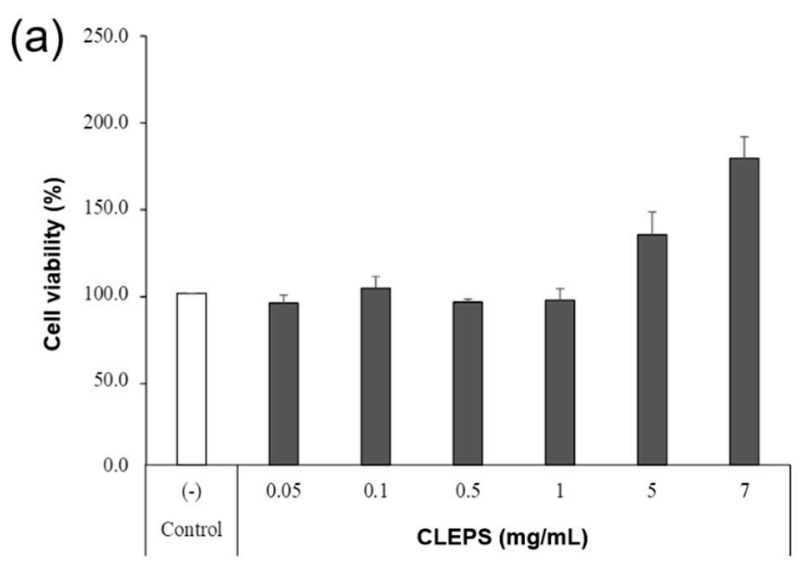

(b)

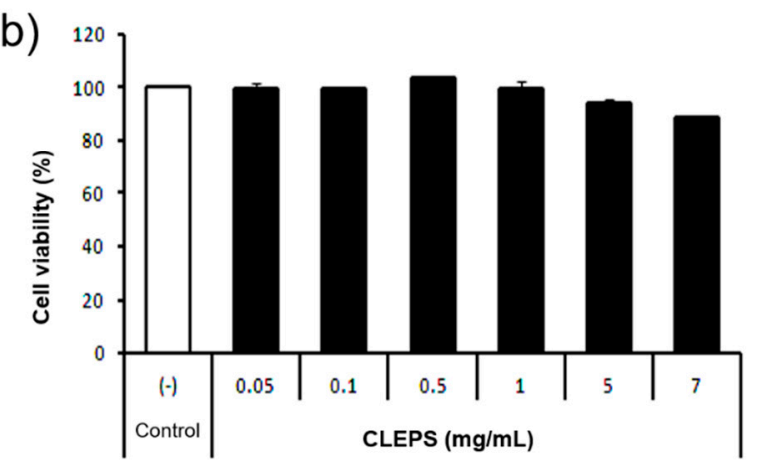

(c)

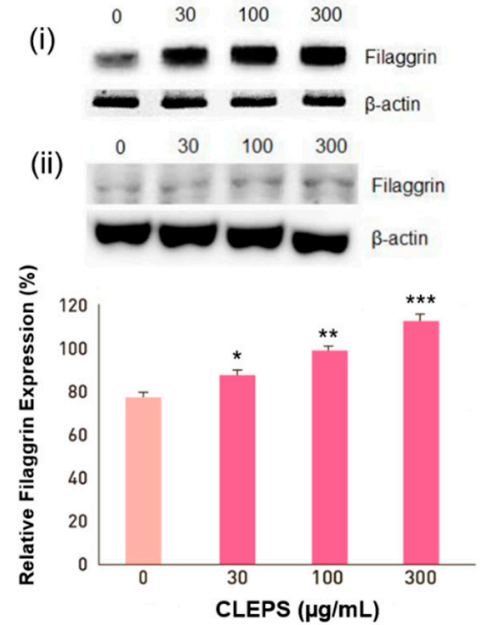

(d)

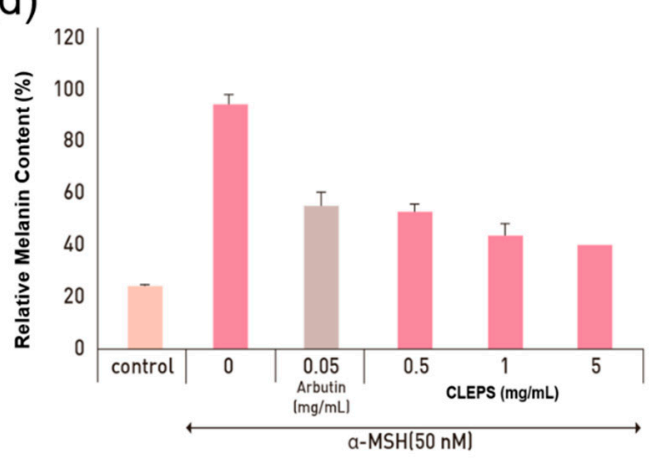

Figure 3. Cell viability and anti-inflammatory tests. Cell viability assays performed with a MTT assay on human dermal fibroblasts (NHDF) (a) and B16 melanoma cells (b). Effects of CLEPS on expression of filaggrin mRNA (i) and proteins (ii) in HaCaT cells (c) $\left(^{*} p<0.05^{* *} p<0.01 * * * p<0.001\right.$ vs. untreated). Melanin inhibition in B16 melanoma cells was evaluated by comparing the change in melanin content (\%) according to the change in absorbance of the CLEPS untreated group with $\alpha-\mathrm{MSH}(\mathbf{d})(p>0.05$ vs. control).

\subsection{Expression Level of Filaggrin}

Filaggrins are an adhesive to hold keratin together, gradually flattening the shape of keratinocytes, increasing the strength of the skin barrier, and strengthening the cohesion between cells in the skin surface [22]. As presented in Figure 3c, when HaCaT cells were treated with CLEPS (30-300 $\mu \mathrm{g} / \mathrm{ml})$, the level of filaggrin expression at $300 \mu \mathrm{g} / \mathrm{ml}$ was significantly increased by $36 \%$ in contrast to the untreated group, confirming CLEPS could enhance or preserve the capability of skin barrier and moisturize through upregulation of filaggrin. To evaluate effective anti-dry skin function via filaggrin upregulation, plant extracts derived from Artemisia princeps [23], Rhodiola crenulate [24], or a mixture of Actinidia arguta and Perilla frutescens [25] were studied, while a fungal metabolite such as GFF [26] were investigated. In this regard, CLEPS would be a new filaggrin-enhancing ingredient based on a fungal metabolite if further developed.

\subsection{Melanogenesis Inhibition Test of B16 Melanoma Cells}

When CLEPS $(0.5,1.5 \mathrm{mg} / \mathrm{mL})$ was added to the $\alpha$-MSH-induced melanocytes, melanin synthesis was effectively inhibited by $43 \%, 54 \%$, and $57 \%$, respectively, in a concentration-dependent manner (Figure 3d). It has been confirmed that CLEPS can downregulate melanin synthesis more efficiently than $50 \mu \mathrm{g} / \mathrm{ml}$ of arbutin (41\%). As an active compound extracted from the bearberry plant in Arctostaphylos, arbutin is a wellknown melanin suppressor in cultured human melanocytes or B16 murine melanocytes [27]. 
Although it is therefore being widely used as a skin-lightening agent in the cosmetic market, many uncertainties remain, i.e., arbutin is a glycosylated hydroquinone that may cause cancer risks [28]. Considering arbutin is a recognized whitening single compound, it is very encouraging that CLEPS not only exhibited a skin-whitening effect by inhibiting the synthesis of melanin, but also showed superior whitening function over arbutin, even though it is an unidentified complex compound.

\subsection{Anti-Inflammation Assay of NO, iNOS, COX2, and TNFa}

When CLEPS $500 \mu \mathrm{g} / \mathrm{mL}$ was treated, the levels of inflammation-related factors, NO (a), iNOS (b), COX2 (c), and TNF $\alpha$ (d) were significantly reduced by $\sim 75 \%, \sim 85 \%, 62 \%$, and $55 \%$, respectively (Figure 4 ). It was confirmed that CLEPS exerts an anti-inflammatory effect by regulating the inflammatory signaling pathway via suppressing the production of $\mathrm{NO}$ and the expression of inflammation-related genes. The potent inhibition of NO and TNF- $\alpha$ activity was comparable to those of commercially available edible mushrooms, such as Enoki, Shiitake, and Oyster, as the most potent anti-inflammatory species among mushrooms $\left(\mathrm{IC}_{50}<0.1 \mathrm{mg} / \mathrm{mL}\right)[29]$.

(a)

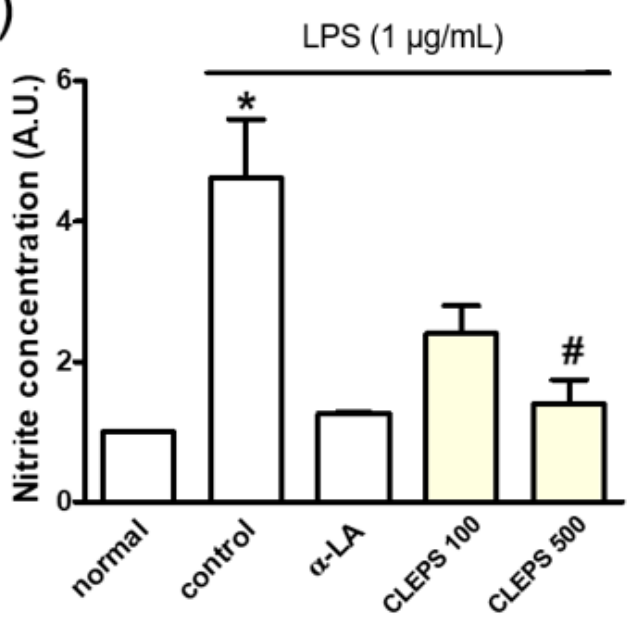

(c)

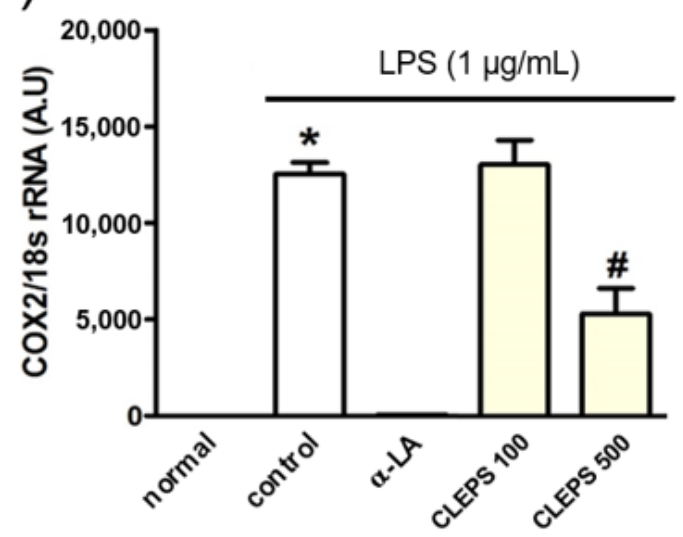

(b)

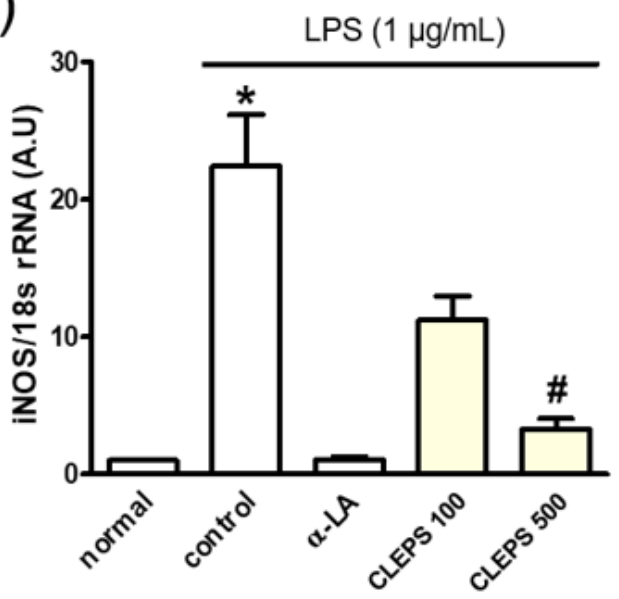

(d)

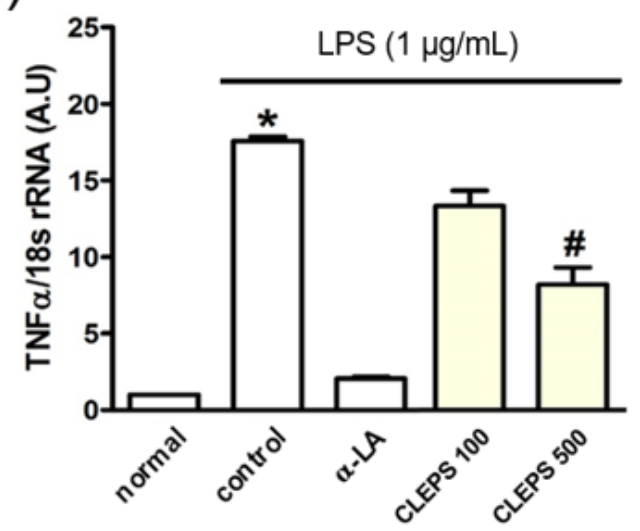

Figure 4. Anti-inflammatory effects of CLEPS (100-500 $\mu \mathrm{g} / \mathrm{mL})$ by inhibiting the inflammatory factors, including NO (a), iNOS (b), COX2 (c), and TNF $\alpha(\mathbf{d}) .{ }^{*} p<0.05$ vs. normal, $\# p<0.05$ vs. control.

\subsection{Synthesis of Collagen and Inhibition of Collagenase}

Collagen is not only a key component supporting skin structure, but it can also directly control the wound microenvironment, serve as a scaffold for cell adhesion and function, or deliver biologically active ingredients to aid wound healing [1]. When damaged or deficient, the skin can wrinkle, deform, or cause skin disease. To confirm the anti-wrinkle 
efficacy of the CLEPS, synthesis of the collagen and inhibition of collagenase assays were performed as shown in Figure 5. Compared with the control groups, the groups treated with $10 \mathrm{ng} / \mathrm{mL}$ of TGF- $\beta$ as a positive control showed a substantial increase in collagen synthesis by $\sim 52 \%$. The collagen synthesis was increased to $27.4 \%, 31.9 \%$, and $65.4 \%$ in the groups treated with CLEPS at concentrations of $0.5,1$, and $5 \mathrm{mg} / \mathrm{mL}$, accordingly in a concentration-dependent manner. PMA is a major ROS generating substance and has been routinely used as an endogenous inducer of superoxide production, which can increase MMP activity in dermal fibroblasts, resulting in extracellular matrix (ECM) protein degradation and premature skin aging [30]. In this work, the MMP-1 proteins were substantially increased after being treated with $50 \mathrm{nM}$ of PMA, while it substantially dropped to $93.4 \%$ in the presence of CLEPS $(5 \mathrm{mg} / \mathrm{mL})$ in a concentration-dependent manner, indicating that CLEPS suppressed the collagenase activity by inhibiting PMAinduced oxidative stress to make NHDF cell death. Thus, it was confirmed that CLEPS could be effective in wrinkle improvement through collagen synthesis and collagenase reduction in skin ECM.

(a)

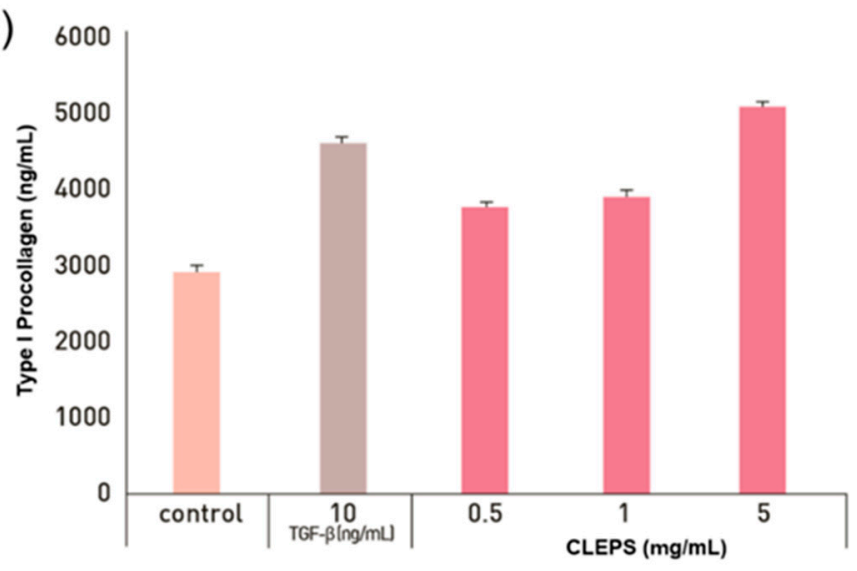

(b)

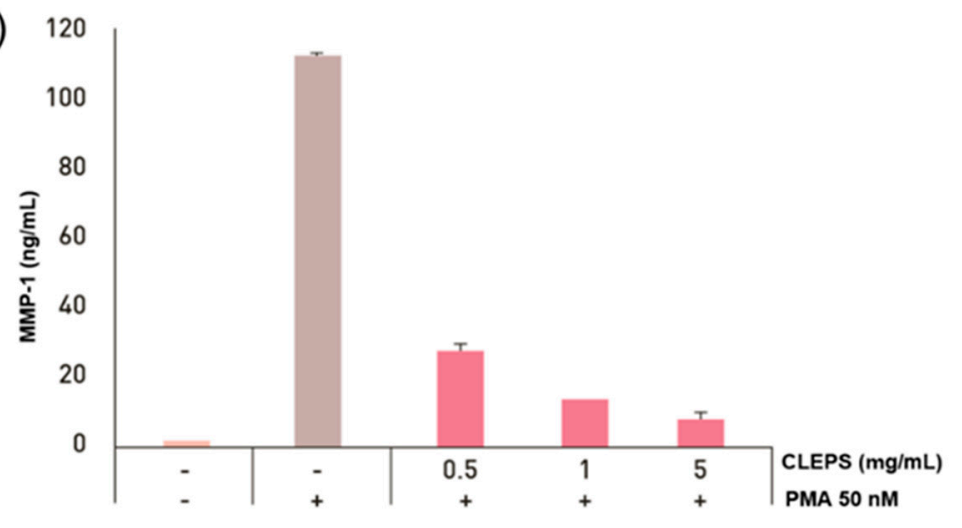

Figure 5. Effect of CLEPS on synthesis of collagen (a) ( $p>0.05$ vs. control) and inhibition of collagenase (b) ( $p>0.05$ vs. no PMA).

\subsection{In Vitro Wound Healing Assay}

ROS-mediated oxidative stress weakens the dermal structural and mechanical integrity of a tissue microenvironment that contributes to age-related skin disorders, such as delayed wound healing [31,32]. To investigate the effect of CLEPS on the wound recovery process, $\mathrm{HaCaT}$ cells were grown in a low serum medium (1\%) (serum starvation) for $0-48 \mathrm{~h}$ at $37^{\circ} \mathrm{C}$. During wound healing assays, cells not only migrate with that gap, but they also multiply. To properly discriminate the migratory capacity of cells, it can be inhibited by treating the cells with the minimal nutrient conditions before creating gaps. As presented in Figure 6, the cells treated with CLEPS at $500 \mu \mathrm{g} / \mathrm{ml}$ exhibited accelerated cell migration up to $\sim 60 \%$ or $\sim 90 \%$ decrease of the wound area after $12 \mathrm{~h}$ or $24 \mathrm{~h}$, correspondingly, as compared to 
control cells. The data revealed that treatment with the CLEPS could contribute to a skin wound healing in a day. Moreover, this result appears to be consistent with the MTT results described above, where CLEPS can aid cell activation in human dermal cells such as NHDF. Therefore, fungal polysaccharide can be a major cell healing effector, as demonstrated in the previous result that the polysaccharide extract of A. auricula-judae showed wound healing effect within $48 \mathrm{~h}$ through the skin cell proliferation mechanism [21].
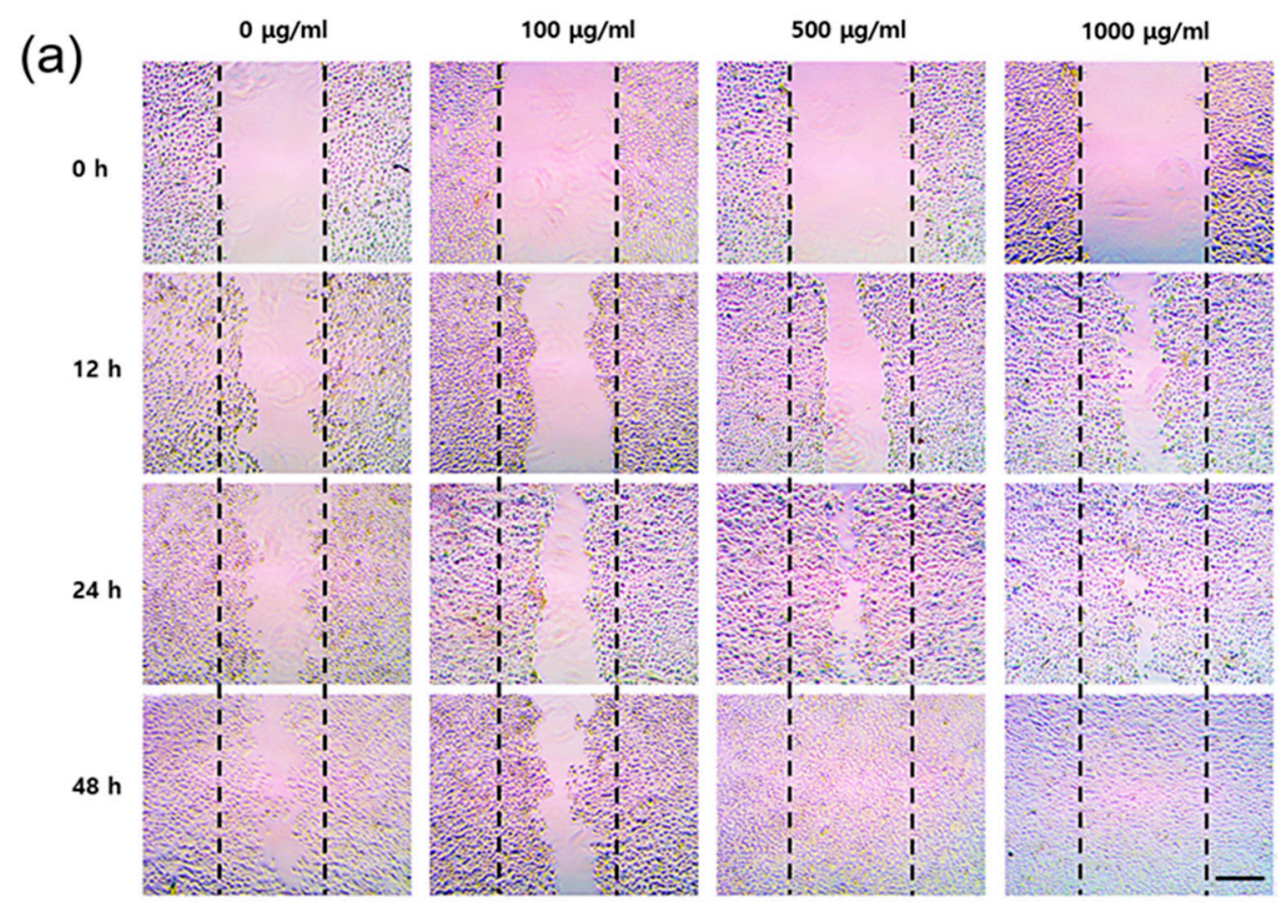

(b)

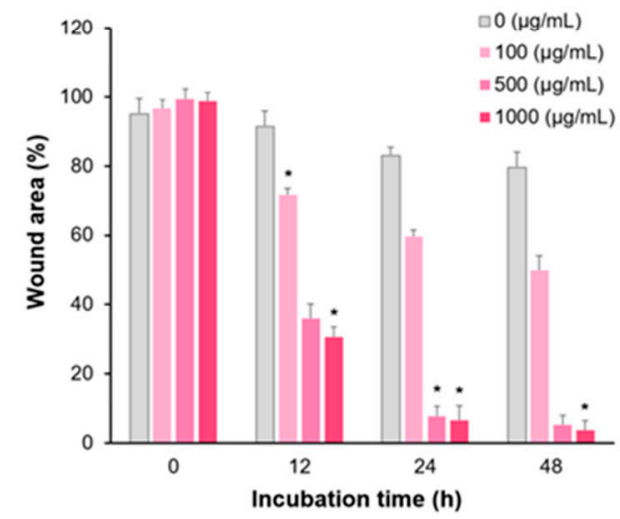

Figure 6. CLEPS-mediated acceleration of wound recovery. A wound healing assay was performed from $0 \mathrm{~h}$ to $48 \mathrm{~h}$ to analyze the effects of CLEPS $(0-1 \mathrm{mg} / \mathrm{mL})$ in HaCaT cells. Scale bar $=100 \mu \mathrm{m}(\mathbf{a})$. Wound recovery by CLEPS treatment was quantified compared to each zero dose group $(* p<0.05)(\mathbf{b})$.

Thus, CLEPS may contain bioactive ingredients in related to anti-aging, anti-oxidation, and anti-inflammatory properties. In the previous initial study, a submerged culture condition for the mycelium biomass and EPS production by C. lacerata were studied [33]. As a result of EPS analyses using HPLC, FT-IR, and NMR, it was found to be composed of polysaccharides, including mannose ( $83.36 \%)$, galactose $(12.54 \%)$, and glucose $(4.10 \%)$. Some flavonoids (e.g., dimethylchalcone) and tremulan sesquiterpenoids (e.g., triphonol) have been also isolated as potent bioactive components [34,35]. However, further research is needed to clarify these active compounds. 


\section{Conclusions}

Taken together, our findings indicated that the CLEPS as a new skincare solution exerts a potential cosmeceutical effect on human skin cell aging through anti-oxidation, antiinflammation, anti-breakdown of skin barrier, and wound healing. Especially, CLEPS not only significantly increased collagen and filaggrin synthesis, but also markedly inhibited the activity of collagenase, possibly indicating that CLEPS could prevent skin barrier damage or skin wrinkles. Although the exact compounds producing these effects are unknown, CLEPS as a novel natural anti-aging ingredient could be used as innovative functional cosmetics. Furthermore, the CLEPS manufacturing process is not an extraction process that mainly uses chemical organic solvents or conducts animal testing, but a bio,eco-friendly, green microbial culture process, which can be well fit with the latest beauty trends in the "vegan" cosmetics market.

Author Contributions: Conceptualization, J.-H.K. and Y.S.K.; data curation and analysis, C.A. and J.-H.K.; project administration, J.-H.K. and Y.S.K.; funding acquisition, Y.S.K.; writing-original draft, J.-H.K.; writing-review and editing, J.-H.K., C.A. and S.D.H. All authors have read and agreed to the published version of the manuscript.

Funding: This research was funded in part by Korea National Food Cluster (FOODPOLIS) Promotion Agency under Korean Ministry of Agriculture, Food, and Rural Affairs, Grant name: "Our Food-To the World (Safety and Efficacy Evaluation)".

Institutional Review Board Statement: Not Applicable.

Informed Consent Statement: Not Applicable.

Data Availability Statement: Not Applicable.

Conflicts of Interest: There are no known conflict of interest associated with this publication and there has been no significant financial support for this work that could have influenced its outcome.

$\begin{array}{ll}\text { Abbreviations } \\ \text { AGEs } & \text { Advanced glycation end-products } \\ \text { CLEPS } & \begin{array}{l}\text { Ceriporia lacerata exo-pharmaceutical substance } \\ \text { exopolysaccharides }\end{array} \\ \text { EPS } & \text { Matrix metalloproteinases } \\ \text { MMPs } & \begin{array}{l}\text { nitric oxide } \\ \text { NO }\end{array} \\ \text { ROS } & \text { reactive oxygen species } \\ \text { LPS } & \text { lipopolysaccharide } \\ \alpha \text {-LA } & \alpha \text {-lipoic acid } \\ \text { iNOS } & \text { inducible nitric oxide synthase } \\ \text { DPPH } & 2,2-\text { diphenyl-1-picryl-hydrazyl-hydrate } \\ \text { ABTS } & 2,2-\text {-azinobis-(3-ethylbenzothiazoline-sulfonic acid) } \\ \text { UV } & \text { Ultraviolet }\end{array}$

\section{References}

1. Parrado, C.; Mercado-Saenz, S.; Perez-Davo, A.; Gilaberte, Y.; Gonzalez, S.; Juarranz, A. Environmental stressors on skin aging. Mechanistic Insights. Front. Pharmacol. 2019, 10, 759. [CrossRef] [PubMed]

2. Rinnerthaler, M.; Bischof, J.; Streubel, M.K.; Trost, A.; Richter, K. Oxidative stress in aging human skin. Biomolecules 2015, 5, 545-589. [CrossRef]

3. Sies, H.; Jones, D.P. Reactive oxygen species (ROS) as pleiotropic physiological signalling agents. Nat. Rev. Mol. Cell Biol. 2020, 21, 363-383. [CrossRef]

4. Gupta, P.L.; Rajput, M.; Oza, T.; Trivedi, U.; Sanghvi, G. Eminence of microbial products in cosmetic industry. Nat. Prod. Bioprospect. 2019, 9, 267-278. [CrossRef] [PubMed]

5. Martel, J.; Ojcius, D.M.; Ko, Y.F.; Chang, C.J.; Young, J.D. Antiaging effects of bioactive molecules isolated from plants and fungi. Med. Res. Rev. 2019, 39, 1515-1552. [CrossRef]

6. Keller, N.P. Fungal secondary metabolism: Regulation, function, and drug discovery. Nat. Rev. Microbiol. 2019, 17, 167-180. [CrossRef] [PubMed] 
7. Meyer, V.; Basenko, E.Y.; Philipp Benz, J.; Braus, G.H.; Caddick, M.X.; Csukai, M.; Vries, R.P.; Endy, D.; Frisvad, J.C.; Gunde-Cimerman, N.; et al. Growing a circular economy with fungal biotechnology: A white paper. Fungal Biol. Biotechnol. 2020, 7, 1-23. [CrossRef]

8. Dufossé, L.; Fouillaud, M.; Caro, Y. Fungi and fungal metabolites for the improvement of human and animal nutrition and health. J. Fungi 2021, 7, 274. [CrossRef] [PubMed]

9. Takahashi, J.A.; Barbosa, B.; Martins, B.A.P.; Guirlanda, C.A.F.; Moura, M. Use of the versatility of fungal metabolism to meet modern demands for healthy aging, functional foods, and sustainability. J. Fungi 2020, 6, 223. [CrossRef] [PubMed]

10. Kumari, M.; Survase, S.A.; Singhal, R.S. Production of Schizophyllan using Schizophyllum commune NRCM. Bioresour. Technol. 2008, 99, 1036-1043. [CrossRef]

11. Miyamoto, K.; Dissanayake, B.; Omotezako, T.; Takemura, M.; Tsuji, G.; Furue, M. Daily fluctuation of facial pore area, roughness, and redness among young Japanese women; beneficial effects of Galactomyces ferment filtrate containing antioxidative skin care formula. J. Clin. Med. 2021, 10, 2502. [CrossRef]

12. Suhara, H.; Maekawa, N.; Kaneko, S.; Hattori, T.; Sakai, K.; Kondo, R. A new species, Ceriporia lacerata, isolated from white-rotted wood. Mycotaxon 2003, 86, 335-347.

13. Lee, J.W.; Gwak, K.S.; Park, J.Y.; Park, M.J.; Choi, D.H.; Kwon, M.; Choi, I.G. Biological pretreatment of softwood Pinus densiflora by three white rot fungi. J. Microbiol. 2007, 45, 485-491.

14. Kim, J.E.; Kim, H.J.; Lee, S.P. Hyperglycemic effect of submerged culture solution of Ceriporia lacerata in streptozotocin-induced diabetic rats. Food Sci. Biotechnol. 2012, 21, 1685-1693. [CrossRef]

15. Kim, J.H.; Park, Y.K.; Kim, J.E.; Lee, S.P.; Kim, B.C.; Jang, B.C. Crude solution of Ceriporia lacerata has a protective effect on dexamethasone-induced cytotoxicity in INS-1 cells via the modulation of PI3K/PKB activity. Int. J. Mol. Med. 2013, 32, 179-186. [CrossRef] [PubMed]

16. Shin, E.J.; Kim, J.E.; Kim, J.H.; Park, Y.M.; Yoon, S.K.; Jang, B.C.; Lee, S.P.; Kim, B.C. Effect of submerged culture of Ceriporia lacerata mycelium on GLUT4 protein in $\mathrm{db} / \mathrm{db}$ mouse. Korean J. Food Preserv. 2015, 22, 893-900. [CrossRef]

17. Choi, J.W.; Shin, E.J.; Lee, S.J.; Kim, Y.H.; Kim, S.R.; Ji, Y.M.; Kim, N.Y.; An, C.H.; Lee, I.H.; Kim, Y.S. Effects of submerged culture of Ceriporia lacerata mycelium on high fat diet-induced diabetic mice with insulin resistance. J. Korean Soc. Food Sci. 2017, 46, 1419-1426. [CrossRef]

18. Kedare, S.B.; Singh, R.P. Genesis and development of DPPH method of antioxidant assay. J. Food Sci. Technol. 2011, 48, 412-422. [CrossRef]

19. Kim, H.J.; Suh, H.J.; Kim, J.H.; Park, S.; Joo, Y.C.; Kim, J.S. Antioxidant activity of glyceollins derived from soybean elicited with Aspergillus sojae. J. Agric. Food Chem. 2010, 58, 11633-11638. [CrossRef]

20. Goh, M.J.; Lee, H.K.; Cheng, L.; Kong, D.Y.; Yeon, J.H.; He, Q.Q.; Cho, J.C.; Na, Y.J. Depigmentation effect of kadsuralignan F on melan-a murine melanocytes and human skin equivalents. Int. J. Mol. Sci. 2013, 15, 1655-1666. [CrossRef] [PubMed]

21. Mapoung, S.; Umsumarng, S.; Semmarath, W.; Arjsri, P.; Thippraphan, P.; Yodkeeree, S.; Limtrakul, P. Skin Wound-Healing Potential of Polysaccharides from Medicinal Mushroom Auricularia auricula-judae (Bull.). J. Fungi 2021, 7, 247. [CrossRef]

22. Brown, S.J.; Mclean, W.H. One remarkable molecule: Filaggrin. J. Investig. Dermatol. 2012, 132, 751-762. [CrossRef] [PubMed]

23. Hirano, A.; Goto, M.; Mitsui, T.; Hashimoto-Hachiya, A.; Tsuji, G.; Furue, M. Antioxidant Artemisia princeps Extract Enhances the Expression of Filaggrin and Loricrin via the AHR/OVOL1 Pathway. Int. J. Mol. Sci. 2017, 18, 1948. [CrossRef] [PubMed]

24. Hashimoto-Hachiya, A.; Tsuji, G.; Murai, M.; Yan, X.; Furue, M. Upregulation of FLG, LOR, and IVL Expression by Rhodiola crenulata Root Extract via Aryl Hydrocarbon Receptor: Differential Involvement of OVOL1. Int. J. Mol. Sci. 2018, 19, 1654. [CrossRef] [PubMed]

25. Lee, W.; Jeong, Y.; Park, J.-H.; Lee, C.H.; Yun, N.; Lee, D.S.; Nam, I.-J.; Kim, J.-D.; Yoon, K.D.; Son, M.; et al. Water-Soluble Extract from Actinidia arguta (Siebold \& Zucc.) Planch. ex Miq. and Perilla frutescens (L.) Britton, ACTPER, Ameliorates a Dry Skin-Induced Itch in a Mice Model and Promotes Filaggrin Expression by Activating the AhR Signaling in HaCaT Cells. Nutrients 2019, 11, 1366.

26. Takei, K.; Mitoma, C.; Hashimoto-Hachiya, A.; Takahara, M.; Tsuji, G.; Nakahara, T.; Furue, M. Galactomyces fermentation filtrate prevents T helper 2-mediated reduction of filaggrin in an aryl hydrocarbon receptor-dependent manner. Clin. Exp. Dermatol. 2015, 40, 786-793. [CrossRef]

27. Jiang, L.; Wang, D.; Zhang, Y.; Li, J.; Wu, Z.; Wang, Z. Investigation of the pro-apoptotic effects of arbutin and its acetylated derivative on murine melanoma cells. Int. J. Mol. Med. 2018, 41, 1048-1054. [CrossRef]

28. Blaut, M.; Braune, A.; Wunderlich, S.; Sauer, P.; Schneider, H.; Glatt, H. Mutagenicity of arbutin in mammalian cells after activation by human intestinal bacteria. Food Chem. Toxicol. 2006, 44, 1940-1947. [CrossRef]

29. Gunawardena, D.; Bennett, L.; Shanmugam, K.; King, K.; Williams, R.; Zabaras, D.; Head, R.; Ooi, L.; Gyengesi, E.; Münch, G. Anti-inflammatory effects of five commercially available mushroom species determined in lipopolysaccharide and interferon- $\gamma$ activated murine macrophages. Food Chem. 2014, 148, 92-96. [CrossRef]

30. Sadowski, T.; Dietrich, S.; Müller, M.; Havlickova, B.; Schunck, M.; Proksch, E.; Müller, M.S.; Sedlacek, R. Matrix metalloproteinase19 expression in normal and diseased skin: Dysregulation by epidermal proliferation. J. Investig. Dermatol. 2003, 121, 989-996. [CrossRef] 
31. Dunnill, C.; Patton, T.; Brennan, J.; Barrett, J.; Dryden, M.; Cooke, J.; Leaper, D.; Georgopoulos, N.T. Reactive oxygen species (ROS) and wound healing: The functional role of ROS and emerging ROS-modulating technologies for augmentation of the healing process. Int. Wound J. 2017, 14, 89-96. [CrossRef] [PubMed]

32. Comino-Sanz, I.M.; López-Franco, M.D.; Castro, B.; Pancorbo-Hidalgo, P.L. The role of antioxidants on wound healing: A review of the current evidence. J. Clin. Med. 2021, 10, 3558. [CrossRef] [PubMed]

33. Kim, J.E. Exopolysaccharide Production and Antidiabetic Effect by Immersion Culture of Ceriporia lacerata. Ph.D. Thesis, Keimyung University Graduate School, Daegu, Korea, 2013.

34. Shan, W.G.; Liang, D.E.; Ying, Y.M.; Zhan, Z.J. Two new tremulane sesquiterpenoids from Ceriporia lacerate, an endophytic fungus of Huperzia serrata. J. Chem. Res. 2012, 36, 365-366. [CrossRef]

35. Ying, Y.M.; Shan, W.G.; Zhang, L.W.; Zhan, Z.J. Ceriponols A-K, tremulane sesquitepenes from Ceriporia lacerate HS-ZJUTC13A, a fungal endophyte of Huperzia serrata. Phytochemistry 2013, 95, 360-367. [CrossRef] [PubMed] 